\title{
EVALUATION OF THE SALIVARY LEVEL OF MIR-21 IN CIGARETTE SMOKERS: CASE-CONTROL STUDY
}

\author{
Shereen $\mathrm{Ali}^{*}$ and Eman Amer**
}

\begin{abstract}
Background: Salivary biomarkers are attractive non-invasive tools for screening oral cancer especially in high risk individuals such as smokers. The present study observed the salivary level of microRNA-21 to verify their value as diagnostic marker for smokers.

Methods: The study sample comprised 40 males: 20 non-smokers and 20 smokers. Whole unstimulated saliva samples were collected. The resulting data was analyzed for any statistical significance.

Results: Smokers had statistically significant higher salivary microRNA-21 level than nonsmokers.

Conclusions: Our study demonstrated elevated levels of salivary microRNA-21 in cigarette smokers. Salivary miR-21 could be a promising new diagnostic marker for cigarette smokers. We recommend conducting further studies to investigate its diagnostic value as a marker for oral cancer susceptibility in cigarette smokers.
\end{abstract}

KEYWORDS: MicroRNA-21, Smokers, Diagnostic marker, Salivary biomarkers.

\section{INTRODUCTION}

Clinical examination and histopathological assessment are still the gold standards for diagnosing oral cancer. However, clinical examination identifies only visible lesions and biopsy is considered an invasive technique. In addition, they can't detect subtle early changes or predict the progress from normal epithelium to carcinoma ${ }^{(1,2)}$.

Detecting salivary biomarkers is a promising non-invasive field for screening and diagnosing oral cancer ${ }^{(2,3)}$. These biomarkers will be more valuable for detecting early epithelial changes especially in high risk individuals ${ }^{(1,2)}$.

Tobacco use is the most established major risk factor of oral cancer with the cigarette being the most intensively consumed form. Many studies confirmed thattobacco users have cytomorphological changes in epithelial cells of clinically appearing normal mucosa ${ }^{(4-7)}$.

* Lecturer, Department of Oral Medicine and Periodontology, Faculty of Oral and Dental Medicine, Cairo University. ** Associate Professor, Department of Medical Biochemistry, Faculty of Pharmacy, Ahram Canadian University. 
Accordingly, searching for non-invasive diagnostic or screening techniques including salivary biomarkers is an important demand for smokers to detect these early changes ${ }^{(8)}$. Various salivary biomarkers were investigated including cotinine, thiocyanate, nicotine, carbon monoxide, oxidants and anti-oxidants. Some of them proved to be specific to smoking only and others not, in addition most of them are not markers for oral cancer $^{(9-13)}$.

Emerging promising biomarkers in the salivary diagnostics are microRNAs (miRNAs). miRNAs are regulators and biomarkers of carcinogenesis ${ }^{(14,15)}$. Oral carcinogenesis is associated with activation of proto-oncogenes and inactivation of tumor suppressor genes partly by the help of miRNAs. In addition, miRNAs regulate various cellular events such as proliferation, apoptosis and invasion ${ }^{(16)}$.

MicroRNA-21 (miR-21) is one of the most known miRNAs to be over expressed in oral cancer, as well as being capable to distinguish between progressing and non-progressing leukoplakias. miR-21 is considered oncogene, it down regulates tumor suppressor genes, thus suppresses apoptosis and promotes cell proliferation ${ }^{(15-18)}$.

Although previous studies evaluated the salivary miR-21 in oral cancer ${ }^{(17,18)}$, there is a scarcity of studies that evaluate this marker in smokers. The current study observed the salivary level of miR-21 to verify its value as diagnostic marker in smokers.

\section{MATERIAL AND METHODS}

\section{Study design}

Observational case-control study.

\section{Study setting and participants: (Figure 1)}

Individuals were recruited from the pool of the out-patient Clinic of Oral Medicine, Periodontology and Diagnosis Department, Faculty of Oral and Dental Medicine - Cairo University.

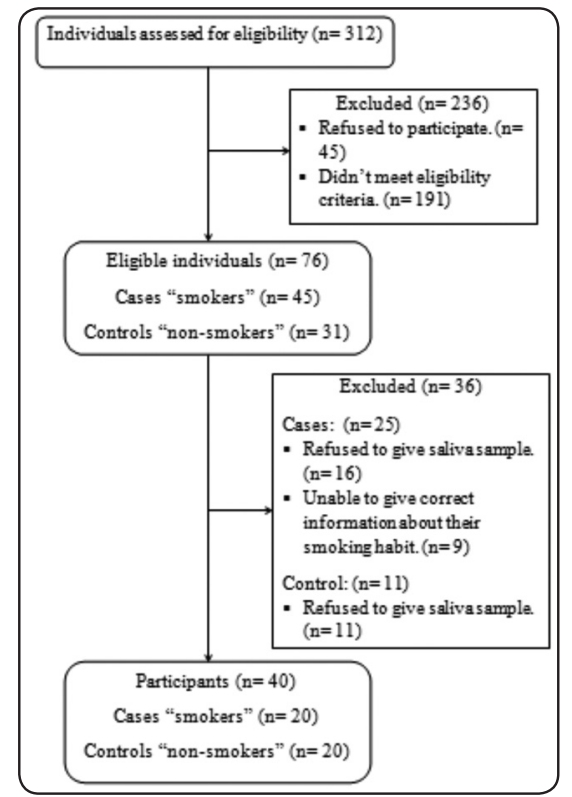

Fig. (1) Participants flowchart

All enrolled individuals fulfilled the eligibility criteria. The inclusion criteria included males of age range (20 - 65) years old. The exclusion criteria included alcohol consumption, forms of tobacco use other than cigarettes as well as diseases namely systemic diseases, oral diseases, dental diseases and periodontal diseases.

To avoid selection bias, the first forty patients fulfilling the eligibility criteria were enrolled in the study. For each individual a full history was obtained followed by thorough clinical examination.The number of cigarettes smoked per day and duration of smoking were recorded, thentotal number of cigarettes was calculated. After full description of the study and the entire procedure anapproved written consent was obtained. This research followed Declaration of Helsinki and was approved by Faculty Research Ethics committee of the Faculty of Oral \& Dental Medicine, Cairo University in September 2016 (number: 16-9-24).

Up to our knowledge, no previous studies investigated the salivary level of miRNA-21 in cigarette smokers. Thus, we have no reference study 
for accurate sample size calculation. Accordingly, the authors decided to recruit 40 males; 20 nonsmoking subjects served as the control group and 20 smoking subjects as a preliminary case-control study.

\section{Salivary sample collection}

A whole unstimulated saliva sample was collected from each individual in the morning. The participants were asked not to eat, brush their teeth, use mouth rinse, or smoke at least two hours prior to sample collection. Each participant was asked to swallow, then tilt their head forward, and expectorate $10 \mathrm{ml}$ of unstimulated whole saliva into a sterile centrifuge tube ${ }^{(13)}$.

\section{Detection of salivary miR-21 by quantitative real time PCR}

The saliva samples were vortexed then centrifuged at $2,600 \times \mathrm{g}$ for 15 minutes at $4^{\circ} \mathrm{C}$. The saliva supernatant was collected, for every milliliter $1 \mu \mathrm{L}(20 \mathrm{U})$ of SUPERase inhibitor was added and kept frozen at $-80^{\circ} \mathrm{C}$.

Total RNA was isolated from saliva supernatant using mirVana miRNA isolation Kit (Applied Biosystems). RNA concentrations were measured byspectrophotometer. cDNA was generated using PrimeScript RT reagent kit (Applied Biosystem) in a $20 \mu$ f final reaction volume containing $0.5 \mu \mathrm{g}$ of RNA, 0.5 $\mu$ l Prime-Script RT enzyme mix, $4 \mu 1$ $5 \times$ PrimeScript buffer and $1 \mu \mathrm{l}$ RT primer, and incubated at $42^{\circ} \mathrm{C}$ for 60 minutes, then at $85^{\circ} \mathrm{C}$ for 5 minutes.

Quantitative real-time PCR assay was performed to evaluate miR-21 expression using SYBR Premix Ex Taq (Applied BioSystem). Primers for miR-21 and endogenous control U6 snRNA were obtained from Applied Biosystems and measured in Step One Plus System supplied by (Applied BioSystem, USA). The cycling was denaturing at $95^{\circ} \mathrm{C}$ for 10 minutes, followed by 45 cycles of denaturation $\left(95^{\circ} \mathrm{C}-15\right.$ seconds $)$, annealing $\left(60^{\circ} \mathrm{C}\right.$ - 30 seconds) and extension $\left(72^{\circ} \mathrm{C}-1\right.$ minute). The relative expression of miR-21 was calculated and normalized using the $2^{-\Delta \Delta}$ tmethod relative to $\mathrm{U} 6$ small nuclear RNA.

\section{Statistical analysis}

The data were described as means and standard deviations. The Kolmogorov-Smirnov test was applied to test normality of the data. Normally distributed data required using parametric paired Student's t-test, while those not normally distributed required using non-parametric Wilcoxon matched pairs test to assess differences between the two groups. Pearson's correlation coefficient was used to determine correlation between salivary miR-21 and the dose as well as duration of smoking in the group of smokers. The significance level was verified at $\mathrm{P} \leq 0.05$. Computerized statistical package SPSS $16.0^{\circledR}$ for Windows (SPSS Inc., Chicago, IL) was used for analyzing the data.

\section{RESULTS}

Each of the two groups consisted of twenty male patients. In group I (non-smokers), the age ranged from 25 to 55 years with mean 38.4. Age range in group II (smokers) was from 23 to 63 years with mean 41.7. No statistical difference wasfound between the two groups regarding age (Table 1).

The smokers had a higher mean salivary miR-21 level $8.4( \pm 4.8)$ compared to thatof the non-smokers which was $1.2( \pm 0.35)$. Statistical analysis showed that this difference was highly significant with $\mathrm{P}$ value 0.0001 (Table 1 Figures 2).

No statistical significant correlation between the mean salivary level of miR-21 at one side and the dose as well as duration at the other side (Table 2). 
TABLE (1) Statistical comparisons between the studied groups

\begin{tabular}{|c|c|c|c|c|}
\hline & Non-smoker & Smoker & Mean Difference & P-value \\
\cline { 2 - 4 } & Mean $( \pm$ SD) & Mean $( \pm$ SD $)$ & 0.32 \\
\hline Age (years) & $38.4( \pm 9.4)$ & $41.7( \pm 12.3)$ & $3.35( \pm 14.57)$ & $<0.0001^{*}$ \\
\hline miR-21** & $1.2( \pm 0.35)$ & $8.4( \pm 4.8)$ & $-7.2( \pm 4.8)$ & $<$ \\
\hline
\end{tabular}

*Statistical significance at p-value $\leq 0.05$.

TABLE (2) Correlation analysis in smokers.

\begin{tabular}{|c|c|c|c|c|}
\hline & $\begin{array}{l}\text { Number of } \\
\text { cigarettes } \\
\text { per day }\end{array}$ & $\begin{array}{l}\text { Duration } \\
\text { (years) }\end{array}$ & $\begin{array}{c}\text { Total } \\
\text { number of } \\
\text { cigarettes }\end{array}$ \\
\hline \multirow{2}{*}{$\begin{array}{l}\vec{\sim} \\
\frac{\alpha}{a} \\
\stackrel{a}{a}\end{array}$} & $\begin{array}{c}\text { Correlation } \\
\text { Coefficient (r) }\end{array}$ & -0.117 & 0.342 & 0.099 \\
\hline & P-value & 0.312 & 0.07 & 0.339 \\
\hline
\end{tabular}

*Statistical significance at p-value $\leq \mathbf{0 . 0 5}$.

\section{DISCUSSION}

The importance of and demands for salivary biomarkers as diagnostic or prognostic markers are increasing because collecting saliva sample is a simple, non-invasive procedure ${ }^{(8)}$.

Among the previously investigated salivary biomarkers for smokers are nicotine and cotinine. Both of them are specific to smokers but not to oral cancer, moreover the technique of saliva collection (stimulated or unstimulated) affects their salivary level ${ }^{(19,20)}$.Salivary levels of carbon monoxide and thiocyanate proved to be affected by other causes not smoking only ${ }^{(19)}$. Although oxidants and antioxidants could be reliable diagnostic biomarkers for smokers, but several precautions should be followed during their detection ${ }^{(21)}$. First, unstimulated whole saliva sample is a better approach than stimulated saliva for measuring these markers. Age, gender, lifestyle and diseases could influence their levels ${ }^{(3)}$.
**Results of the non-parametric Wilcoxon matched pairs test.

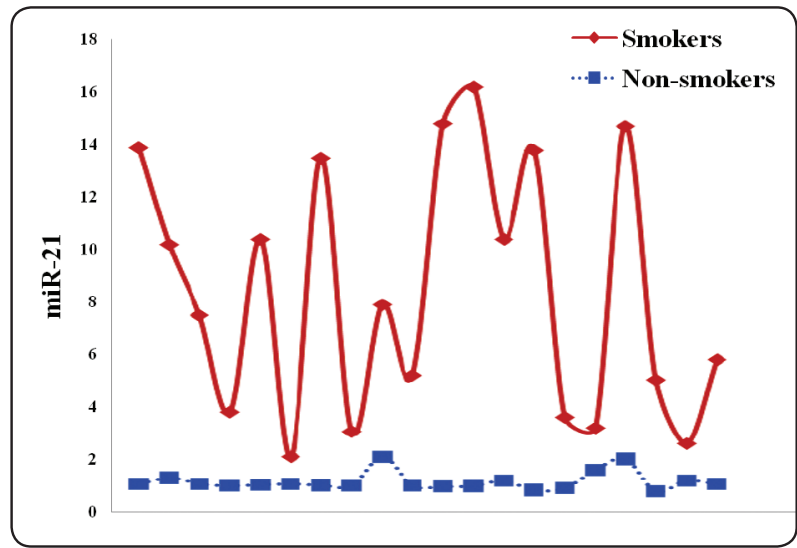

Fig. (2) Individual salivary miR-21 levels of the studied groups

In addition, dietary consumption of anti-oxidant rich food and drinks could affect the salivary of oxidants and anti-oxidants ${ }^{(3,21)}$. All these confounders can affect the general is ability of these biomarkers as a diagnostic aid in smokers.

The present study observed the salivary level of miR-21 to verify their value as diagnostic marker for smokers. Our results demonstrated a statistically highly significant increased salivary miR-21 level in smokers. These results were consistent with Suzuki et al. (2016) who reported elevated serum miR-21 level in cigarette smokers than non-smokers; they stated that nicotine deregulated the expression of $\operatorname{miR}-21^{(21)}$.

These results together with the fact that miRNAs are involved in the process of carcinogenesis by influencing cellular proliferation and apoptosis ${ }^{(16,17)}$ may possibly support a notion that miR-21 could be a specific salivary biomarker for oral cancer susceptibility in smoker. In addition, 
miR-21 is stable in saliva samples with no restrictions regarding the method of sample collection (either unstimulated or stimulated) that provide them advantage over other salivary markers including the well known oxidants and anti-oxidants ${ }^{(1)}$.

\section{CONCLUSION}

- Our study demonstrated elevated levels of salivary miR-21 in cigarette smokers.

- Salivary miR-21 could be a promising new diagnostic marker for cancer susceptibility in cigarette smokers.

\section{RECOMMENDATIONS}

- Diagnostic accuracy studies are required to test the diagnostic value of salivary miR-21 as a marker for oral cancer in cigarette smokers.

\section{ACKNOWLEDGEMENTS}

The authors would like to thank Dr. Safaa Mohamed Abd El-Moteleb, statistics consultant at Research center, Faculty of nursing, Cairo University for her help in the statistical analysis and Dr. Alaa Abou Shousha, Resident of Oral Medicine, Faculty of Oral and Dental Medicine, Cairo University for her help in the recruitment of participants.

\section{REFERENCES}

1. Yang Y, Li Y, Yang X, Jiang L, Zhou Z, Zhu Y (2013). Progress risk assessment of oral premalignant lesions with saliva miRNA analysis. BMC Cancer13: 129.

2. Ishikawa $S$, Sugimoto M, Kitabatake K, Sugano A, Nakamura M, Kaneko M, Ota S, Hiwatari K, Enomoto A,Soga T, Tomita M,\& Iino M (2016). Identification of salivary metabolomic biomarkers for oral cancer screening. Sci Rep 6: 31520 .

3. Peluso I, Raguzzini A (2016). Salivary and Urinary Total Antioxidant Capacity as Biomarkers of Oxidative Stress in Humans. Patholog Res Int 2016: 5480267.

4. Sham A, Cheung L, Jin L, Corbet E (2003). The effects of tobacco use on oral health. Hong Kong Med J9: 271-277.
5. Karthikeyan R, Reddy BS, Sherlin HJ, Anuja N, Ramani P, Chandrasekar T, Ganesan S, Viswanathan P (2008). Stromal changes in apparently normal mucosa of smokers and pan chewers - a multiparametric approach. Braz J Oral Sci 7(26): 1602-1608.

6. Khandelwal S, Solomon MC (2010). Cytomorphological Analysis of Keratinocytes in Oral Smearsfrom Tobacco Users and Oral Squamous Cell Carcinoma Lesions - A Histochemical Approach. Int J Oral Sci 2(1): 45-52.

7. Souto GR, Caliari MV, Lins CE, de Aguiar MC, de Abreu MH, Mesquita RA (2010). Tobacco use increase the number of aneuploid nuclei in the clinically healthy oral epithelium. J Oral Pathol Med 39: 605-610.

8. Jessie K, Pang W, Abdul Rahim ZH, Hashim OH (2010). Proteomic Analysis of Whole Human Saliva Detects Enhanced Expression of Interleukin-1 Receptor Antagonist, Thioredoxin and Lipocalin-1 in Cigarette Smokers Compared to Non-Smokers. Int J Mol Sci 11: 4488-4505.

9. Etter JF, Due TV, Perneger TV (2000). Saliva Cotinine Levels in Smokers and Non smokers. Am J Epidemiol 151: 251-258.

10. Abdolsamadi HR, Goodarzi MT, Mortazavi H, Robati M, Ahmadi-Motemayel F (2011). Comparison of Salivary Antioxidants in Healthy Smoking and Non-smoking Men. Chang Gung Med J 34: 607-611.

11. Nuca C, Amariei C, Badea V, Zaharia A, Bucur L, Arendt C (2012). Salivary cotinine-biomarker of tobacco consumption in the assessment of passive smoking prevalence.Farmacia 60: 662-674.

12. Bakhtiari S, Azimi S, Mehdipour M, Amini S, Elmi Z, Namazi Z (2015). Effect of Cigarette Smoke on Salivary Total Antioxidant Capacity. J Dent Res Dent Clin Dent Prospect 9(4): 281-284.

13. Falsafi P, Nasrabadi E, Nasrabadi H, Khiyavi RK, Eslami H (2016). Comparison of Total Antioxidant Capacity and Vitamin C in Smokers and Non-smokers. Biomed \&Pharmacol J 9(1): 299-304.

14. YoshizawaJM, Wong DT (2013). Salivary MicroRNAs and Oral Cancer Detection. Methods MolBiol 936: 313-324.

15. Min A, Zhu C, Peng S, Rajthala S, Costea DE, Sapkota D (2015).MicroRNAs as Important Players and Biomarkers in Oral Carcinogenesis. Biomed Res Int 2015: 186904.

16. Kolokythas A, Miloro M, Zhou X (2011). Review of MicroRNA Deregulation in Oral Cancer. Part I.J Oral Maxillofac Res 2(2):e1. 
17. Kolokythas A, Miloro M, Zhou X (2011). Review of MicroRNA Proposed Target Genes in Oral Cancer. Part II.J Oral Maxillofac Res 2(2):e2.

18. Hedback N, Jensen DH, Specht L, Fiehn A-MK, Therkildsen MH, Friis-Hansen L, Dabelsteen E, Buchwald CV (2014). MiR-21 Expression in the TumorStroma of Oral Squamous Cell Carcinoma: An Independent Biomarker of Disease Free Survival. PLoS ONE 9(4): e95193.

19. Jarvis MJ, Tunstall-Pedoe H, Feyerabend C, Vesey C, Saloojee Y (1987). Comparison of Tests Used to Distinguish Smokers from Non smokers. Am J Public Health 77:1435-1438.
20. Robson N, Bond AJ, Wolff K (2010). Salivary nicotine and cotinine concentrations in unstimulated and stimulated saliva. AJPP 4: 61-65.

21. Kusano C, Ferrari B (2008). Total Antioxidant Capacity: a biomarker in biomedical and nutritional studies.J Cell MolBiol 7(1): 1-15

22. Suzuki K, Yamada H, Nagura A, Ohashi K, Ishikawa H, Yamazaki M, Ando Y, Ichino N, Osakabe K, Sugimoto K, Hamajima N, Inoue T (2016).Association of cigarette smoking with serum microRNA expression among middle-aged Japanese adults.Fujita Medical Journal 2 (1): 1-5. 